\title{
Carotid artery stenosis and stroke: controversies in prevention and treatment
}

The main causes of ischemic carotid-territory stroke are thromboembolism from the internal carotid or middle cerebral artery (25\%), small vessel intracranial disease (25\%) and cardiac embolism (20\%) (1). About one in four strokes is classified as "cryptogenic" stroke, that is, a brain infarction without a clear etiology despite extensive investigation $(1,2)$. Overall, about $10-15 \%$ of all strokes follow thromboembolism from a previously asymptomatic $>50 \%$ internal carotid artery stenosis $(1,2)$. Every year there are approximately 1,400,000 strokes in Europe (1) and 800,000 strokes occurring in the USA (2). Stroke is a major cause of death and disability. Stroke also imposes an enormous financial burden on healthcare systems and societies $(1,2)$. Therefore, the identification of specific preventive measures and the optimization of treatment modalities are essential to lower the exceedingly high stroke and death rates, as well as the considerable stroke-associated costs.

There are several discrepancies and controversial issues in the management of carotid artery stenosis and the prevention of carotid-related strokes. For instance, a major controversial issue is the optimal management of asymptomatic carotid stenosis $(3,4)$. The introduction and rigorous employment of a group of conservative measures which constitute the so-called "best medical treatment" (e.g., smoking cessation, weight reduction, management of hypertension and hypercholesterolemia, as well as adoption of a healthy diet) is essential both in symptomatic and in asymptomatic carotid patients $(1,3,4)$. However, for some asymptomatic patient subgroups, best medical treatment alone is not adequate to prevent the development of future strokes (5). For these individuals, a prophylactic carotid endarterectomy (CEA) should be considered $(1,5)$. The accurate identification of individuals at high future risk is an issue which has been widely debated. There is accumulating evidence that the therapeutic approach of asymptomatic patients should be individualized, taking into consideration several issues, among others patient's age/life expectancy, mobility, preferences/expectations, gender, etc. (6).

Another controversial issue is the management of internal carotid artery occlusion (7-9). Although it was previously thought that internal carotid artery occlusion is a benign condition, this issue has been challenged by recent evidence that some carotidrelated strokes may occur in the presence of an ipsilateral carotid artery occlusion (7-9). Stenosis progression or plaque rupture with secondary thrombosis is thought to be the most common cause of acute internal carotid occlusion $(10,11)$. The finding that internal carotid artery occlusion may be the culprit lesion in approximately $40 \%$ of carotid-related strokes in patients without previous symptoms (7) raises important concerns regarding the optimal management of asymptomatic carotid patients.

Importantly, when considering the optimal management of extracranial internal carotid artery occlusion, it is essential to differentiate patients with $v s$. without intracranial large vessel occlusion (8). In the presence of a concomitant intracranial vessel occlusion, early thrombolysis of the intracranial lesion is the single most important parameter contributing to a favorable outcome of the ischemic stroke (8). In the absence of a concomitant intracranial artery occlusion, the management is not clear as there are no randomized trials on the topic (8). An intervention is probably warranted in patients at high risk of progressive clinical worsening, as well as in those with significant neurologic deficits and a large penumbra (8).

The role of inflammation in carotid plaques and the optimal way to detect its presence are additional controversial issues $(12,13)$. The presence of inflammation in a carotid plaque increases the risk of plaque instability and the development of thromboembolic cerebrovascular complications (12). Thus, timely identification of carotid plaque inflammation before the occurrence of stroke is crucial. This is made possible with the aid of novel modalities such as fluorescent-labeled dual-ligand microparticles of iron oxide and multidetector magnetic resonance imaging $(12,13)$. Identification of patients with carotid plaque inflammation would have significant implications with regards to decision-making, as these patients could potentially be candidates for a prophylactic carotid intervention.

Another controversial and much debated issue is the role of carotid artery stenting (CAS) in the management of patients with carotid artery stenosis $(14,15)$. Although CAS has emerged as a less invasive alternative to CEA, data from real-world clinical studies suggest that CAS is associated with considerably higher stroke/death rates compared with CEA and is therefore not an equal alternative to CEA for many carotid patients $(14,16)$. Fortunately, a novel technique called transcarotid artery revascularization (TCAR) with carotid flow reversal, has already demonstrated some promising results $(17,18)$ and may hopefully provide the answer for high-risk patients requiring a carotid revascularization procedure. Current evidence suggests that TCAR is associated with similar outcomes when compared with the gold standard, CEA $(17,18)$. A randomized controlled trial in the 
future comparing CEA vs. TCAR is essential to establish TCAR as an effective treatment modality for carotid stenosis patients.

Prevention and treatment of ischemic carotid-related strokes is a research priority. All controversial issues should be addressed to optimize patient outcomes. The current series are the second part of two series on the prevention and treatment of carotid artery stenosis and carotid-related strokes. Hopefully, these two series will help to answer many of the current questions and to resolve some of the controversial issues on the topic.

\section{Acknowledgements}

Funding: None.

\section{Footnote}

Provenance and Peer Review: This article was commissioned by the editorial office, Annals of Translational Medicine for the series "Carotid Artery Stenosis and Stroke—Prevention and Treatment Part II". The article did not undergo external peer review.

Conflicts of Interest: The author has completed the ICMJE uniform disclosure form (available at http://dx.doi.org/10.21037/ atm-21-149). The series "Carotid Artery Stenosis and Stroke-Prevention and Treatment Part II" was commissioned by the editorial office without any funding or sponsorship. KIP served as the unpaid Guest Editor of the series. The author has no other conflicts of interest to declare.

Ethical Statement: The author is accountable for all aspects of the work in ensuring that questions related to the accuracy or integrity of any part of the work are appropriately investigated and resolved.

Open Access Statement: This is an Open Access article distributed in accordance with the Creative Commons AttributionNonCommercial-NoDerivs 4.0 International License (CC BY-NC-ND 4.0), which permits the non-commercial replication and distribution of the article with the strict proviso that no changes or edits are made and the original work is properly cited (including links to both the formal publication through the relevant DOI and the license). See: https://creativecommons.org/licenses/by-nc$\mathrm{nd} / 4.0 /$.

\section{References}

1. Naylor AR, Ricco JB, de Borst GJ, et al. Editor's Choice - Management of Atherosclerotic Carotid and Vertebral Artery Disease: 2017 Clinical Practice Guidelines of the European Society for Vascular Surgery (ESVS). Eur J Vasc Endovasc Surg 2018;55:3-81.

2. Virani SS, Alonso A, Benjamin EJ, et al. Heart Disease and Stroke Statistics-2020 Update: A Report From the American Heart Association. Circulation 2020;141:e139-596.

3. Spence JD. Management of asymptomatic carotid stenosis. Ann Transl Med 2020;8:1262.

4. Fernandes E Fernandes J, Mendes Pedro L, Gonçalves I. The conundrum of asymptomatic carotid stenosis-determinants of decision and evidence. Ann Transl Med 2020;8:1279.

5. Paraskevas KI, Veith FJ, Ricco JB. Best medical treatment alone may not be adequate for all patients with asymptomatic carotid artery stenosis. J Vasc Surg 2018;68:572-5.

6. Lanza G, Giannandrea D, Lanza J, et al. Personalized-medicine on carotid endarterectomy and stenting. Ann Transl Med $2020 ; 8: 1274$.

7. Klarin D, Cambria RP, Ergul EA, et al. Risk factor profile and anatomic features of previously asymptomatic patients presenting with carotid-related stroke. J Vasc Surg 2018;68:1390-5.

8. Mayer L, Grams A, Freyschlag CF, et al. Management and prognosis of acute extracranial internal carotid artery occlusion. Ann Transl Med 2020;8:1268.

9. Paciaroni M, Caso V, Venti M, et al. Outcome in patients with stroke associated with internal carotid artery occlusion. 
Cerebrovasc Dis 2005;20:108-13.

10. Malhotra K, Goyal N, Tsivgoulis G. Internal Carotid Artery Occlusion: Pathophysiology, Diagnosis, and Management. Curr Atheroscler Rep 2017;19:41.

11. Lall A, Yavagal DR, Bornak A. Chronic total occlusion and spontaneous recanalization of the internal carotid artery: Natural history and management strategy. Vascular 2020. doi:10.1177/1708538120978043.

12. Ding S, Zhang M, Zhao Y, et al. The role of carotid plaque vulnerability and inflammation in the pathogenesis of acute ischemic stroke. Am J Med Sci 2008;336:27-31.

13. Chan JM, Monaco C, Wylezinska-Arridge M, et al. Imaging vulnerable plaques by targeting inflammation in atherosclerosis using fluorescent-labeled dual-ligand microparticles of iron oxide and magnetic resonance imaging. J Vasc Surg 2018;67:1571-83.

14. Paraskevas KI, Veith FJ. Who benefits from carotid artery stenting? J Vasc Surg 2017;65:1553-4.

15. Paraskevas KI, Beard JD, Veith FJ. Carotid artery stenting: it's all about appropriate patient selection and keeping to the indications. Expert Rev Cardiovasc Ther 2014;12:783-6.

16. Paraskevas KI, Kalmykov EL, Naylor AR. Stroke/Death Rates Following Carotid Artery Stenting and Carotid Endarterectomy in Contemporary Administrative Dataset Registries: A Systematic Review. Eur J Vasc Endovasc Surg 2016;51:3-12.

17. Malas MB, Dakour-Aridi H, Kashyap VS, et al. TransCarotid Revascularization with Dynamic Flow reversal versus Carotid Endarterectomy in the Vascular Quality Initiative Surveillance Project. Ann Surg 2020. [Epub ahead of print]. doi: 10.1097/ SLA.0000000000004496.

18. Paraskevas KI, Antonopoulos CN, Kakisis JD, et al. An updated systematic review and meta-analysis of results of transcervical carotid artery stenting with flow reversal. J Vasc Surg 2020;72:1489-1498.e1.

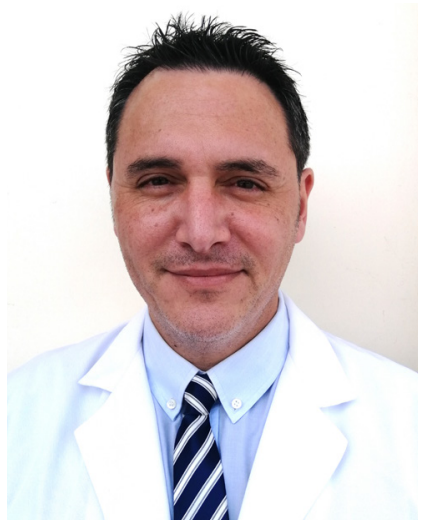

Kosmas I. Paraskevas

Kosmas I. Paraskevas, MD

Department of Vascular Surgery, Central Clinic of Athens, Athens, Greece.

(Email: paraskevask@hotmail.com)

Submitted Jan 11, 2021. Accepted for publication Feb 23, 2021.

doi: $10.21037 / \mathrm{atm}-21-149$

View this article at: http://dx.doi.org/10.21037/atm-21-149

Cite this article as: Paraskevas KI. Carotid artery stenosis and stroke: controversies in prevention and treatment. Ann Transl Med 2021;9(14):1200. doi: 10.21037/atm-21-149 